\title{
A remaking pedagogy: adaptation and archetypes in the child's multimodal reading and writing
}

\author{
Richard Berger ${ }^{\mathrm{a}}$ and Marketa Zezulkova ${ }^{\mathrm{b}}$
}

${ }^{a}$ Centre for Excellence in Media Practice, Bournemouth University, Poole, UK; ${ }^{b}$ Institute of Communication Studies and Journalism, Charles University, Prague, Czech Republic

\section{ABSTRACT}

This paper proposes combining theories about, and practices of, using archetypes and adaptation in education for the purposes of multimodal literacy learning. Within such contexts, children of primary school age act as readers, performers and researchers, exploring and analysing existing adaptations of archetypal stories and images across time, space and platforms, as well as writers constructing and producing their own adaptations of archetypes in varying forms. Our suggestions are that 'revisiting' and 'remaking' existing texts and practices in the multimodal primary classroom can be a route to a deeper and more sophisticated learning experience, and one which challenges current definitions of reading, writing and literacy.

\section{ARTICLE HISTORY}

Received 6 April 2016

Accepted 10 April 2016

\section{KEYWORDS}

Adaptation; archetypes; remaking; multimodal; literacy; pedagogy

\section{Introduction}

Compulsory schooling is arguably prone to dichotomies such as those dividing reading from viewing, as well as literacy from media and digital literacies, whilst allocating media platforms and texts into fixed groups based on their role in formal education and their perceived value and appropriateness to the child's life, learning and development. Policy fields, too, are drawn along very narrow curricula lines; governments and education departments will often have a different strategy for literacy, art and IT, for example. Similarly, literacy and media literacy theories and practice alike are 'still very much wedded to the idea of medium specificity' (Berger and Woodfall 2012, 117). Further, Berger and Woodfall go on to criticise that young people's 'social practices are [instead] largely (if not always) non-medium specific - [as] they fail to recognise the misguidedly imagined distinctions between different media' (Berger and Woodfall 2012, 119). Woodfall and Zezulkova (2016) have observed a similar phenomenon among primary school children, suggesting that they

do not readily turn to platform as a means of understanding media, and that they are quick to complicate and override reductionist view of their media lives, even when the educational setting and pre-supposition may privilege one medium, or group of media over another.

In addition, research shows that children repeatedly return to the same texts, over and over again, continually remaking and re-contexutualising their own textual experiences (Willett 2014).

A number of studies have therefore focused on reconceptualising reading and writing by opening them to the child's multimodal modes of 'composing and consuming' (Wissman and Vasudevan 2012 , 325) which are 'interconnected in very complex, multifaceted ways using a plethora of image, sound, and print' (Tierney, Bond, and Bresler 2006, 361), as well as 'movement $[\ldots]_{\perp}$ and gesture' (Walsh 2011, 106). Marsh and Millard (2000), for example, suggest that 
[c]hildren are constantly engaged in decoding the reality represented in the world around them, interpreting it according to their own sociocultural practices and experiences and then encoding it, using whatever range of materials are available to them (...) [and hence] challenging prevailing notions of what constitutes literacy within the usual confines of a ( ... ) classroom. (48)

We take our cue here from Marsh and Millard - for 'materials' read 'texts' as the central focus of this paper - for as the primary school teacher Krause (2015) notes that, '[a]s educators, we need to make ourselves aware of the harmonious blend of authentic modes of communication afforded to children through our increasingly multimodal literacy environment' (72).

Whilst criticising that 'traditional learning models today struggle to meet our learners where they are ready and willing to learn' (Fleming 2013,370), an opportunity is increasingly seen in transmedia learning that shall benefit from '[t]he multi-modal, multi-sited nature of many transmedia productions [that] challenge children to use varied textual, visual, and media literacy skills to decode and remix media elements' (Herr-Stephenson, Alper, and Reilly 2013, 2). This approach aims at reflecting children reaching across 'media platforms - from television to records, books, stuffed toys, public performances, feature films, and much more' by focusing on transmedia stories and characters popular among young children (Jenkins 2013 , 4). Willett $(2005,143)$ similarly notes that '[m]aking use of their media experiences in the classroom allows children to express themselves, not just as students, but also as social individuals' revealing to the adult that in their experience media stories and characters overshadow any single dominant media platform. Yet we do not argue for simply undertaking transmedia approach, which might still over-valorise media platforms (Woodfall and Zezulkova 2016), instead we explore and discuss the pedagogic potential of adaptation and archetypes in multimodal literacy learning that is more people- than media-centric (Gauntlett 2008).

The discussion here will begin with exploring theories and practices of adaptation and archetypes in the context of children's learning and media experience, leading into a critical account of their shared revisiting and remaking nature that could be applied to primary-level education and child's multimodal literacy learning.

\section{Adaptation}

Adaptation scholars have long advocated the pedagogic potential of their subject; for writers such as Thomas Leitch, an understanding of adaptation is 'essential' for a literacy education while he points out that adaptation studies focuses on both reading and writing: 'students who become more proactive in creating their own texts will find themselves not only writing with greater authority but speaking and performing more inventively, fearlessly, and constructively' $(2010,11)$. Similarly, Cutchins (2010) argues that, 'studying literature via adaptations offers our students a better, more effective way of studying literature' (87), while Berger (2010) and Şahin and Raw (2010) propose a pedagogy whereby students are given material to re-write. But, all of these interventions and debates are taking place with the narrow conventions of the high school, or university, literature curriculum. To date, there is a lack of research in how adaptation can be effectively used as a pedagogic tool in the primary school classroom, unfettered to a formal literature curriculum.

This strikes us as odd, for any cursory look at children's media demonstrates that adaptation is a dominant discourse. To take a (slightly) medium-specific detour to underscore this point, looking at the top-20 children's films from October 2015, five are based on 'classic' children's books (Beauty and the Beast, The Jungle Book, The Little Mermaid, 101 Dalmatians and Peter Pan); two are based on wellknown folk stories of unknown origin (Cinderalla and Sleeping Beauty); one is based on a physical toy (Lego - League of Justice); one is based on a late-Victorian classic novel (Hotel Transylvania); one is based on a contemporary children's story (Peppa Pig) and at least two have themselves become source material for other texts, in these cases musical theatre (The Lion King and Frozen). For some of these films, 2014 was not the first year of release (Snow White is over 60 years old, and Dracula was written in 1897). But, these texts are constantly released and refreshed for different formats, 
and now circulate on every screen imaginable, suggesting that repetition and finding new audiences in each new generation is a key driver (officialcharts.com, 2015).

So, while it is clear that children's media is littered with adaptations of all kinds - from films and television programmes based on the canon of 'classic' children's literature, to videogames and board games - the role of a dominant media, or a primary text, has less utility. Each variant of a story only serves to further the narrative appeal of a favourite text, or character. As Cartmell (2007) notes, '[c] hildren, unlike adults, love to re-read their favourite stories' (169). And it is this demand for repetition, which is ignored in education (which hurries from text-to-text, from subject-to-subject), which has most influenced our approach.

This then take us to a place where education and learning can be loosened from its mediumspecific moorings - but not for the purposes of serving a general 'media literacy' education. Collins (2010) suggests that electronic media has fundamentally changed our definitions of reading and literacy: 'we are all curators now of words and images' (266). So, in response, our approach here is an attempt to do just that, by using adaptation and remaking as a sophisticated pedagogic tool which deepens our understanding of how children approach different texts in a way which challenges these conventional definitions of 'reading', 'writing' and 'literacy'.

Indeed, while most adaptations (and by association, adaptation studies) are concerned with bringing a well-loved novel to a screen, or remaking a popular existing work, this is still a fairly asynchronous process. With children's media, however, transmedia texts operate far more fluidly, and widely across different media platforms, far more synchronously. At first glance, it may look as if a film or television programme is the primary platform in any media franchise, with toys and games forming secondary, or adjunct, material. However, in his study advocating an 'off-screen studies' Gray (2010) argues that for many children, the story resides in the toys and games (what he calls 'paratexts') and the relationship between different media becomes far more plural:

Granted, the existence of the film or program [sic] usually remains a precondition for the paratext's existence, and thus the film or program [sic] remains important, but it does not do its work alone, nor will it necessarily be responsible for all of a text's popular meanings. (175)

When a child plays with a toy or game based on a popular media franchise, or enacts scenes from a favourite media text, they are 'performing' their own adaptation. Therefore a great deal of children's 'play' can be conceived of as remaking, or re-writing; similar to the ways in which fanfic writers fill in 'gaps' (Jenkins 2006) in their favourite texts, children are also often performing a textual act, and one which embodies Fiske's (1992) notions of producerly or even Barthes' definitions of writerly (1974) texts: '[texts] have to be pen, to contain gaps, irresolutions, contradictions, which both allow and invite fan productivity' (Fiske 1992, pp. 41-42). That these types of performances are still under-represented in the literature for either education or adaptation/literacy is for us a cause for concern, as the adaptation of stories and characters offers productive new learning opportunities and experiences.

A rare exception for this perhaps is the work of the arts education research centre, DARE, at the University of London, which has explored the adaptation of texts into computer games, produced by children - for example,Playing Shakespeare and Playing Beowulf projects. They argue that 'the whole process is multimodal and multiliterate [... ] involv[ing] visual design, writing in different genres, sound, music, speech, and simple programming within the limits of the rule-editor' (Burn 2007, 19, emphasis in original). Yet we would suggest that this approach is still single-medium centred and over-preoccupied with literacy and literary learning through play.

Giving teachers a thorough understanding of adaptation across transmedia stories, can position increasingly ubiquitous learning technologies as connected platforms, which can be 'rewired' as entry/exit points in transmedia stories, for the purpose of more meaningful learning experiences and engagement. When compared to transmedia learning, an adaptation pedagogy can be used not only to facilitate learning across different (but connected) platforms, but also across time (history) and space (sociocultural variations). In the types of performance play we describe that 
children often repeatedly enact moments from their favourite texts, repetitively, suggesting a type of 'collective psychology' among children. Indeed, play can be the beginning of a conversation (dialogue) which children begin to have with different texts and experiences. The repetitive nature of this activities can be a process whereby each performance is honed and improved, as the child strives to be more 'faithful' to the source material, such as the song, 'Let It Go', from Frozen. Positions of fidelity aside, it is worth taking some time to now consider the types of 'universal' archetype characters and archetypal stories, which are in abundance in children's media experiences, and resonate with their 'collective consciousness' (Samuels 2004).

\section{Archetypes}

Émile Durkheim (1893 [2012]) defines this collective or common consciousness as '[t]he totality of beliefs and sentiments common to the average members of a society', or a community (39). Jung (1936/37 [1968]) agrees with Durkheim to an extent, in that in addition to 'personal conscious' is 'collective conscious'. He further suggests that alongside personal unconscious there also is 'collective unconscious, which however does not develop individually [or socially] but is inherited' (43). To take a slight step-back, Jung belonged to the psychoanalytic school of thought and agreed with its founder Sigmund Freud on the matter of personal unconscious as being something 'made up essentially of contents which have at one time been conscious but which have disappeared from consciousness through having been forgotten or repressed' (Jung 1936/37 [1959], 42).

One's personal consciousness, that one is aware of, is 'not total psyche' (Jung 1936/37 [1959]), as according to Jung 'people live on only one or two floors of a large apartment building which is our minds, forgetting the rest' (Dunne 2012, 105). Jung, however, split with Freud and his followers when he broadened the theory of unconsciousness with collective unconscious and archetypes. Jung (1936/ 37 [1968]) writes that 'there exists a second psychic system of a collective, universal, and impersonal nature which is identical in all individuals, ( ... ) consist[ing] of pre-existent forms, the archetypes' (43). Samuels (2004) then readily summarises the two strands of collective unconscious, body and culture:

Of course there is collective psychology. We all possess the same bodies, the same hormones, the same operators, the same brain structure. So isn't it obvious? This is the body argument of collective unconscious; that we will all function similarly, if not in the same way psychologically in a given situation. $[\ldots]$ This is very powerful and scientifically discussable idea. That out of our human bodies comes human psychology shared by all. [... $]_{A}$ The culture aspect is much less scientifically discussable, but much more fascinating. [... $]_{\mathrm{S}}$ All over the world, at all times, our similarities lead to similar culture products. Fairy tales, myths, rituals, religious practices, and emotions can be all understood in that way.

Taking the body strand argument as relatively straightforward, further attention is required on the cultural nature of collective unconscious connected to archetypes. Jung (1936/37 [1959], 43) ascribes the initial cultural idea of 'psychic unity of mankind' to the anthropologist Bastian (1860) who explored elementary or primordial thoughts. Yet he equally referred to other fields of knowledge, such as Mayer's (1844) physical thesis, which have similarly recognised and named the phenomenon. Inspired by these writings and through research expeditions to East Africa and India, Jung defined archetypes as images and stories whose 'origins can only be explained by assuming them to be deposits of the constantly repeated experiences of humanity' (1917/1926/1943 [1983], 70).

These archetypes are, however, not 'genetic buttons waiting to be pushed' (Haine 187), instead they are 'a kind of readiness to produce over and over again the same or similar mythical ideas' (Stevens 1982, 70), causing that certain themes and symbols keep reappearing and repeating themselves over time and space in both people's experiences as well as stories and art they create and share. For Umberto Eco, this repetition is fundamental to the archetype, for it, 'serves to [... ] indicate a pre-established and frequently reappearing narrative situation, cited or in some way recycled by innumerable other texts' $(1998,200)$. For, as Jung has also states (1936/37 [1959]), '[i]n the end we dig up the wisdom of all ages and peoples, only to find that everything most dear and precious to 
us has already been said in the most superb language' (16), and further comments on the influential role of archetypal images and stories in cultural/media texts as follows (1922 [2003], 96):

Whoever speaks in primordial images speaks with a thousand voices; he enthrals and over-powers, while at the same time he lifts the idea he is seeking to express out of the occasional and transitory into the realm of the everenduring. He transmutes our personal destiny into the destiny of mankind, and evokes in us all those beneficent forces that ever and anon have enabled humanity to find a refuge from every peril and to outlive the longest night.

Following Jung's collective unconscious, primordial images and archetypes, a rise was given to archetypal literary criticism in the 1930s that begun with Baudkin's Archetypal Patterns in Poetry: 210 Psychological Studies of Imagination (1934) and peaked in the 1940s and 1950s with Frye's Anatomy of Criticism: Four Essays (1957). Another field of study that has greatly benefited from Jung's theories is comparative mythology within which Campbell's seminal and influential work The Hero with a Thousand Faces (1949) originated. Campbell's central argument suggests that there is something in every text which is inherently reproducible, or adaptable. This has been also recognised within advertising industry and political marketing, where archetypes are used to 'mediate between products and customer motivation by providing an intangible experience of meaning' (Marks and Pearson 2001, 17). The authors give an example of Apple Inc. logo that 'evokes the first act of rebellion in the Garden of Eden, a powerful distillation of the brand's iconoclastic identity' (Marks and Pearson 2001, 24) and further argue that 'many politicians who fail to get either elected or re-elected never establish a consistent archetypal identity' (Marks and Pearson 2001, 20).

Primary school teachers preoccupied with children as consumers and citizens, as were those involved in our research, can therefore equally benefit from using archetypes in their pedagogy. As Harris, Mattson, and Ourada $(1999,131)$ found, 'archetypes are a great way to get young readers thinking about how story characters and situations relate to everyday lives' and using (media) texts popular among children facilitates learning about archetypes that does not overwhelm or bore them. The authors discovered that although they used, for instance, a Power Ranger to illustrate the hero archetype and the Burger King Crown as the ruler archetype, 'the students began recognizing [sic] archetypes on their own, for example, President Clinton as Ruler' (Harris, Mattson, and Ourada 1999).

The hero (or heroine) archetype and his/her journey necessarily involves the wise old man (or woman), which are the two archetypes that, according to Jung (1936/37 [1959]), belong among the historically most prominent archetypes. The archetypal hero journey that starts with a call to adventure, which the hero at first refuses (Campbell 1949 [2008]), but then begins the quest which symbolises the individuation of self (Von Franz 1964), is most widely known for its influence on George Lucas' Star Wars original film series, and subsequent ever-expanding story-world (1977present). It is easily identifiable in the past and current storytelling and life experiences, particularly in children's literature. Among these experiences is according to Mayes (2005a) also teacher-student educational relationship. As he describes (2005a, 34):

[T] he teacher' and 'the student' are themselves archetypal figures. [... $]_{\Lambda}$ Throughout our lives, we are involved in educational acts - as teachers, students, and often both. No human culture has ever been founded or perpetuated without education about everything. $[\ldots$... Something so fundamental to creating and sustaining individuals and cultures is necessarily archetypal.

Mayes (2005b) clarifies that 'the hero soon meets a wise old man or woman, someone who had already completed his or her own archetypal quests long ago when he or she was young' (126). He continued,

the wise ones tantalize [sic] their young charges with riddles, conundrums, and oracles, thereby teasing [the hero] out of the smug certainties of their previous worlds, [which] requires the young hero to seek a newer world by seeking a higher wisdom. (Mayes 2005b, 127) 
Through archetypes such as hero, wise old man, child, mother and caregiver, children can be invited to explore and reflect on their own life, development and learning as well as adults' role within it. Jung (1928 [2014]) cautioned educational theorists and practitioners, saying 'I must warn you again most emphatically that it would be very unsound to apply these methods directly to children' (58), because as Jones (2013) clarified,

Jung assumed a sophistication of self-reflection that is developmentally unlikely in childhood [ $\ldots$ ] [as i]t involves not only the capacity to reflect on one's feelings, anxieties, or motives (which school-aged children can do), but also one's realization $[s i c]$ and desire for personal growth. (13)

However, an increasing number of research demonstrates children's desire for personal growth and for being actively involved in the construction of their (media and school) life (e.g. Markström and Halldén 2009; Corsaro 2014).

Therefore, it could be argued that use of archetypes in multimodal literacy learning has a potential of drawing upon stories and experiences as a truly interconnected phenomenon, addressing 'the problem [which] has been our belief in the idea of "the media" and its separation from ourselves' (McDougall 2011). Robertson (1963) argued in her book Rosegarden and Labyrinth: A Study in Art Education that 'art is a way of extending and coming to terms with experience itself' (195). She collected a sample of 3400 child paintings, of which themes were carefully selected by her and assigned to her own as well as to other 12 teachers' students. Robertson (1963) observed that children 'were often, though not always, painting the same subject, but it was not the repetition of pit tips and waterfalls, but rather some way of seeing it which seemed to jump out at me' (27). She argued that being involved in artistic production, through which archetypical experiences of the world were emerging, allowed children to understand experience is not something that happens to them but rather something that they can shape - which points towards a mode of revisiting and remaking.

\section{Revisiting: combining archetypes with adaptation for reading}

We will further express here that the combination of archetypes and adaptation has a potential of making literacy education situated and media literacy education spiral, whilst reuniting them into a singular multimodal literacy learning and teaching. To begin with children as readers, we must return to our argument about the importance of repetition in the context of spiral education within which children revisit the same concepts repeatedly, 'building upon them until the student has grasped the full formal apparatus that goes with them' (Bruner 1973, 13). Each (re)visit shall be more challenging and demanding, and we argue that it should also be newly situated in order to reflect the children's current individual and collective sociocultural life.

Situated learning 'attempts to define everything about an individual in relation to environmental aspects associated with learning' (Taylor and MacKenney 2008, 144), media included. Schön (1983) described it as reflective dialogue with a situation in which knowledge and skills are developed in the context of activities, contexts and cultures in which they are learnt and used (Visser 2011). The child arguably has a good sense of his or her media interests and tastes being shifted alongside maturing and life-cycle, as well as about the changing nature of trends and preferences they participate in, adopt and shape. Revisiting the same texts might therefore become deeply problematic, whereas revisiting archetypes in their distinct adaptions relevant to both the child's immediate life, and the teacher's pedagogic and curricular goals represents a great opportunity for multimodal literacy learning in primary school classrooms and beyond.

Children's media also often adhere to Campbell's Hero with Thousand Faces, archetype, with many adopting a 'quest' narrative (i.e. some stories popular with children - and therefore adapted and repurposed continually - combine the archetypes of children/childhood with the archetypal quest narrative). In this way, stories such as The Wizard of $\mathrm{Oz}$ and Alice in Wonderland, in Umberto Eco's phrase, allow 'the archetypes [to] hold a reunion' $(1986,208)$. In terms of adaptation, adults are perhaps more concerned about being 'faithful' to a source text: 
In most Disney films, fidelity to the text is openly flaunted; indeed, as is frequently observed, the ambition of a Disney adaptation is to usurp the source - so that the film triumphs over its literary original, and, for most viewers, it is the film rather than the text which is original. $(2007,169)$

Whereas child appreciates the potential multiple entry (and exit) points in any transmedia story and is not prone to reductionism, unless imitating adult popular discourses distinguishing media and separating them from lived experience (Zezulkova 2015; Woodfall and Zezulkova 2016), part of which must be performance play, and another which could (and should) be learning.

Archetypes occur in other non-narrative media, the popularity of which invites appropriations into screen-based narrative media. This further suggests to us that children's performance play can, in and of itself, be conceived of as 'text' and as such offers potential in being augmented by the 'official' media. Combined with conglomeration and the economies of scale, children's performance play has been aggregated into texts as diverse as the Pirates of the Caribbean franchise (based on a theme-park ride), Pokémon: the first movie (based on a card game) and The Lego Movie (based on a toy and videogame). In writing about films based on games, Leitch $(2007,261)$ suggests that:

[T] he film adds a linear narrative. $[. .$.$] Y Yet it would be a mistake to say that the film adds a narrative to a non-$ narrative original, for the game itself is narrative in the sense that it provides a starting point, a single foreordained solution, and myriad possible paths by which the solution may be reached. In activating some of these paths and supressing others, the film does not narrativize [sic] the game but converts its multifoliate narrative structure into a somewhat more Cartesian or Aristotelian structure with a single middle to complement the game's single beginning and end.

This suggests that the archetypes buried in children's off-screen media are the very reason they are appropriated (and therefore re-ignited) in screen-based versions. The popularity of videogames and now games designed for mobile platforms have only further deepened children's relationship with, and lived experience of, media texts. But if for Leitch the 'starting point' is film - with same being for videogames in the DARE research - then for children's transmedia multimodal experiences, the starting point can be anywhere along a continuum of experiences and platforms, which offer multiple intervention sites for the educator.

We will use the child archetype to discuss this further, not only because in children's media, children are archetypes, but also because the experience of being a child is immediately and directly relevant to all primary school children. The child archetype occurs throughout children's media; in fact it is difficult to locate any media text aimed at a child audience which does not feature children, or childhood, in someway - if only as a 'absent' off-screen presence (such as 'Andy' in Toy Story). Childhood and adulthood are also often central themes in children's media. Among the original child subarchetypes, we can easily identify in children's media are the 'wounded child' archetype, such as Dean Stockwell in The Secret Garden; the 'abandoned' or 'orphan child' central to Charles Dickens's work; the magical child such as is featured in The Little Prince and Alice in Wonderland; the 'nature child' archetype similar to Tarzan and Mowgli; the 'divine child' such as the infant Jesus Christ or Little Buddha, and 'eternal child' archetype as embodied by characters such as Peter Pan.

As all Jungian archetypes do, these child archetypes and their subversions have a side that 'points down-wards, partly negative and unfavourable, partly chthonic, but for the rest merely neutral [shadow]' (Jung 1936/37 [1959], 231). Jung claimed that everyone has shadows - 'parts of ourselves we don't like, don't know, or don't want to know' (Dunne 2012, 106). Indeed it seems that the latest adaptation trend in children's media is to focus on the well-known fictional characters' childhood shadows, while exploring why they grew up to be, or to be perceived as, 'mean' and 'evil'; for example, the musical Wicked or the film Maleficent.

To be drawing upon these complex and conflicting child archetypes has a value far beyond narrow constructs of 'reading', as well as the analysis and evaluation of texts as something separate from us, as McDougall (2011) criticises. These archetypes service a dialogue which resonate with our own beliefs about, and experience of, childhood. Although as Jung warns us (see Hancock 2008), the archetype child should never be mistaken for the real thing, the experiences and relationships it 
represents are embedded in our collective consciousness of childhood as well as in our collective unconscious of what is nowadays believed to be a childhood. Through and together with interpreting the child archetype and exploring its varying adaptations over time, space and media, the child is invited to revisit his/her understanding and experience of childhood, each time being challenged further by enclosing more details about sociocultural, political and economic construction of child/ adult and childhood/adulthood. Here then the child as whole is developing multimodal literacy in the context of his/her and the others' individual and collective life. Therefore an aggregation of children's transmedia experiences can help with understanding of how children and childhood is constructed in media texts, and how child audiences respond to them, and ultimately add to them.

\section{Remaking: combining archetypes with adaptation for writing}

Although the organisation of beginning, middle and the end of story was for a long-time believed to be itself archetypal (Hillman 1983), this is unhelpful when applied to the multi-entry and exits points of a typical to children's transmedia experience, as much as it is to contemporary writing and reading practices. Children engage with stories in non-linear fashion and that is how they (re)produce them on school playgrounds, through the medium of repetitive performance play, when 'the source text/ artefact is not drawn upon in an extended manner' (Marsh 2014,125). In this way the children act as 'authors of their own games' (Burn 2014, 18). Whilst the linear structure that once seemed to be archetypal is now under revision due to transmedia, what remains are the archetypal characters and stories. This represents a challenging, but potentially a rewarding, opportunity for not only today's, but more sustainable multimodal literacy learning.

Performance play then can be conceptualised as 'text' and for many children the entry point of a conversation they will have repeatedly with other texts. This further problematises the narrow curriculum boundaries which define current literacy learning in primary schools. In short, current teaching methods ignore these dialogs, and position texts as closed and fixed systems. Even those who take a more plural view cannot help themselves in referencing other similar texts in this exchange:

The frontiers of a book are never clear-cut: beyond the title, the first lines, and the last full stop, beyond its internal configuration and its autonomous for, it is caught up in a system of references to other books, other texts, other sentences: it is a node within a network. (Foucault 2003, 25-26)

The work of Mikhail Bakhtin is perhaps more useful here, particularly his notion of a polyphonic dialogue, where all voices (or situated 'utterances') have equal authority; Bakhtin also recognises the performative aspects of such a dialogue, which for him:

[E]nergises from within the very mode in which the discourse conceives of its object and its means of expressing it transforming the semantics and the syntactical structure of the discourse. Here the dialogical reciprocal orientation becomes, so to speak, an event of discourse itself, animating it and dramatizing it from within all of its aspects. (in Todorov 1984, 60)

Here Bakhtin identifies a textual plurality of unmerged voices and consciousness, within a meta-narrative, or sphere of ideas. This analysis then serves to position writing (and rewriting) and reading as more active modes to that perhaps proposed by both Barthes and Foucault, but here the writers and reader are more alert to the dialogical: the array of voices the text reproduces, interrogates, amplifies and answers. Every utterance then is part of a much wider social and historical context; these utterances resonate with past and present usages.

This goes some way in explaining the popularity of adaptations and remakes in children's media, and why texts are continually returned to and reconstituted by children in their performance play, which education and teaching now needs to account for as both (re)writing and reading. Adaptations for children are not created for children across different platforms simultaneously, but also across distinct historical periods and spaces sociocultural spaces as archetypes are. These textual experiences can account for different point of views on the same archetypes - also spiral, as they can revisit the 
same archetypes over and over again. This heteroglossic approach offers up creative and vocational opportunities of spending less time on story plot whilst investing more learning effort into understanding genre, technique, perspective, context, aesthetics, ethics, morality and more.

Performance play continually remakes and (re)writes media, but should not be viewed as the beginning, middle or end of a dialogue which then moves elsewhere, but instead we would argue that reading, re(writing) and watching media texts across multiple platforms are all part of the same conversation. The problem occurs when education policy is only interested in one or two platform-bound elements of this dialogue. The transmedia nature of children's textual lives now contains opportunities for children to add and create in ways not possible just a decade ago. The plethora of different media platforms have blurred medium-specific lines to such an extent, many media theorists cannot now agree what 'television' constitutes in the transmedia age.

For children, this does not matter, as we have shown, their performance play is very platform agnostic, and their remaking of texts very promiscuous. The transmedia world has created a 'usersphere' (Berger and McDougall 2015) where the accepted demarcation lines between media and texts no longer apply. As a consequence, neither do the practices and processes, which came to define the medium-specific era. If new technology has - in a non-deterministic way - created new spaces where stories (and learning) can flourish, and places where children and young people can be creative, then surely education policy and practice needs to now undergo a similar revolution? This education policy, pedagogy and practice was created in an analogue asynchronous mediumand subject-specific world; education policy and pedagogy now needs to be 'remade' for a digitally synchronous one.

If we can reconstitute performance as acts of reading, writing and ultimately (re)making, then there is much to learn perhaps from drama education, than literacy education. The play or life drama 'as a whole $[. .$.$] ] is a lived experience' (Fink 1960, 97, 99):$

For play is itself a fundamental phenomenon of existence. [...] We play with the serious, the authentic, the real. We play with work and struggle, love and death. We even play with play. [... ] Joy reigns in it as undisputed master at each moment, carrying it forward and giving it wings. [...] It is a joy rooted in the most special $[$. ... ], activity, open to many interpretations. It can include profound sadness, a tragic suffering. It can embrace the most striking contraries. $L$...], [M]oved to tears we may be, we smile at the comedy and tragedy which are our life and which the play represents to us. (Fink 1960, 101)

Buber (1937 [2013]) further argues that '[t]he theatre is an exemplar of life: it completes the human drama by making it whole', whilst stressing the Bakhtinian dialogic relationship between theatre and the human drama as a negotiation that does not seek 'agreement or unanimity' (Courtney 1989, 58) and neither does the child's plural and diverse media experience. Although play is 'always a process that has a meaning' (Fink 1960,99), it resists determinism as it is not a code to be decoded but a 'labyrinth' of meaning (Eco 1984, 56) that requires - and thus nurtures - multimodal literacy and that may reveal to us as educator the stories and textual experiences children are living out. For as Hillman (1978) asks 'where can the heart go to school?', perhaps applying an archetypal approach to primary education can move us closer in understanding the rich nature of children's textual lives, in a transmedia world.

\section{Conclusion}

Those of us who work in education, and are engaged in education research, at whatever level, need to now work towards remaking what we mean when we use the terms 'reading', 'writing' and 'literacy'. While, we would agree with Collins when he argues that: 
We also would go further and propose that children have a far more complex and sophisticated relationship with media texts than is currently given credit, and one which education and formal learning does not (yet) account for, let alone aggregate into current pedagogic practice. Researching how children appropriate, re-create, remake and adapt favourite character archetypes and archetypal narratives may reveal much about the ways in which children relate to their life-world, and each other. If we can also consider a definition of reading and writing which now includes activities such as performance play, and which cover-off the full range of media experiences, then the opportunities for learning opens-up to new horizons.

However, education has much to do to move away from narrow curricula and platform-centred learning. Online learning environments and technologies, coupled with considered pedagogic interventions, can play their part in being one of many entry/exist points in children's transmedia experiences; yet they cannot be taught and learnt in isolation as if separated from 'other' media. Teachers, educators and education policy-makers must now understand what archetypes are mobilised by children's transmedia experiences, and why, but in way which no longer fixed to any one medium or platform. Understanding 'now', how children use media to respond to their own notions of identity and childhood, means that the educators of the future will be more successful in educating the students of tomorrow.

\section{Disclosure Statement}

No potential conflict of interest was reported by the authors.

\section{References}

Barthes, R. 1974. S/Z. Oxford: Blackwell.

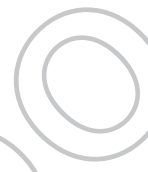

Bastian, A. 1860. Der Mensch in der Geschichte [Man in History]. 3 Vol. Leipzig.

Baudkin, M. 1934 [1963]. Archetypal Patterns in Poetry: Psychological Studies of Imagination. Oxford: Oxford University Press.

Berger, R. 2010. "Never Seek to Tell Thy Love: E-adapting Blake in the Classroom." In Redefining Adaptation, edited by D. Cutchins, L. Raw, and J. M. Welsh. Lanham: The Scarecrow Press.

Berger, R., and J. McDougall. 2015. "Et Tu Media Education? Citizen Four, The Panoptic Web and the new Usersphere." The Media Education Research Journal 6 (1): 5-12.

Berger, R., and A. Woodfall. 2012. "The Digital Utterance: A Crossmedia Approach to Media Education." In Crossmedia Innovations: Texts, Markets, Institutions, edited by I. Ibrus, and A. Scolari. Frankfurt: Peter Lang.

Bruner, J. S. 1973. The Relevance of Education. New York: Norton.

Burn, A. 2007. "Writing' Computer Games: Game-Literacy and New-Old Narratives." http://www.pauldowling.me/ litcomict/papers/Burn.pdf.

Burn, A. 2014. "Children's Playground Games in the New Media age." In Children's Games in the new Media age: Childlore, Media and the Playground, edited by A. Burn, and C. Richards, 1-30. Farnham: Ashgate.

Campbell, J. 1949 [2008]. The Hero with a Thousand Faces. Novato: New world library.

Cartmell, D. 2007. "Adapting Children's Literature." In The Cambridge Companion to Literature on Screen, edited by D. Cartmell, and I. Whelehan. Cambridge: Cambridge University Press.

Collins, J. 2010. Bring on the Books for Everybody: How Literary Culture Became Popular Culture. London: Duke University Press.

Corsaro, W. 2014. The Sociology of Childhood (4th ed). Los Angeles: Sage Publications.

Cutchins, D. 2010. "Why Adaptations Matter to Your Literature Students." In The Pedagogy of Adaptation, edited by D. Cutchins, L. Raw, and J. M. Welsh. Lanham: The Scarecrow Press.

Dunne, C. 2012. Carl Jung: Wounded Healer of the Soul. London: Watkins Publishing.

Durkheim, E. 1895[1982]. The Rules of Sociological Method. New York: The Free Press.

Eco, U. 1998. Faith in Fakes: Travels in Hyperreality. London: Vintage.

Fiske, J. 1992. "The Cultural Economy of Fandom." In The Adoring Audience, edited by L. A. Lewis. London: Routledge.

Fleming, L. 2013. "Expanding Learning Opportunities with Transmedia Practices: Inanimate Alice as an Exemplar." Journal of Media Literacy Education 5 (2): 330-377.

Foucault, M. 1991. "What is an Author?" In The Foucault Reader, edited by P. Rabinow. London: Routledge.

Frye, N. 1957[2000]. Anatomy of Criticism: Four Essays. Princeton, NJ: Princeton University Press.

AQ19

AQ20

AQ21

1

AQ22 
Gauntlett, D. 2008. "Participation Culture, Creativity, and Social Change." Presentation at the University of Westminster. Accessed April 5. http://www.youtube.com/watch?v = MNqgXbl1_o8.

Gray, J. 2010. Show Sold Separately: Promos, Spoilers and Other Media Paratexts. New York: New York University Press. Hancock, S. 2008. The Child That Haunts Us. London: Routledge.

Harris, K., D. Mattson, and S. Ourada. 1999. "Forever Jung." School Library Journal 3: 131.

Herr-Stephenson, B., M. Alper, and E. Reilly. 2013. "T for Transmedia: Learning Through Transmedia Play." USC Annenberg Innovation Lab and Cooney Center. Accessed December 5. http://www.joanganzcooneycenter.org/publication/t-isfor-transmedia.

Hillman, J. 1983. Healing Fictions. Barrytown: Station Hill Press.

Jenkins, H. 2013. "Introduction." In Transmedia: Learning Through Transmedia Play, edited by B. Herr-Stephenson, M. Alper, and E. T. Reilly. USC Annenberg Innovation Lab and Cooney Center. Accessed December 5. http://www. joanganzcooneycenter.org/publication/t-is-for-transmedia/

Jones, R. A. 2013. "On the 'art and Science' of Personal Transformation: Some Critical Reflections." In Jung and Educational Theory, edited by I. Semetsky, 13-21. West Sussex: Willey-Blackwell.

Jung, C. G. 1917/1926/1943 [1983]. "On the Psychology of the Unconscious." In The Essential Jung, edited by A. Storr, 6871. New York: MJF Books.

Jung, C. G. 1922[2003]. "On the Relation of Analytical Psychology to Poetry." In The Spirit in man, art and Literature, edited by C. A. Jung, 75-97. Oxon: Routledge Classics.

Jung, C. G. 1928[2014]. "Child Development and Education." In The Development of Personality, edited by H. Read, M. Fordham, and G. Adler, 47-62. London: Routledge.

Jung, C. G. 1936/37 [1968]. The Archetypes and the Collective Unconscious (2nd ed.). London: Routledge.

Krause, M. B. 2015. "Connecting, Creating, and Composing: A Shared Multimodal Journey." Journal of Media Literacy Education 6 (3): 71-80.

Leitch, T. 2007. Film Adaptation and its Discontents: From Gone with the Wind to the Passion of the Christ. Baltimore, MD: Johns Hopkins University Press.

Leitch, T. 2010. "How to Teach Film Adaptations and Why." In The Pedagogy of Adaptation, edited by D. Cutchins, L. Raw, and J. M. Welsh. Lanham: The Scarecrow Press.

Marks, M., and C. Pearson. 2001. The Hero and the Outlaw: Building Extraordinary Brands Through the Power of Archetypes. Columbus: McGraw-Hill Education.

Markström, A.-M., and G. Halldén. 2009. "Children's Strategies for Agency in Preschool." Children \& Society 23 (2): $112-122$.

Marsh, J. 2014. "The Relationship Between Online and Offline Play: Friendship and Exclusion." In Children's Games in the New Media age: Childlore, Media and the Playground, edited by A. Burn, and C. Richards, 109-132. Farnham: Ashgate. Marsh, J., and E. Millard. 2000. Literacy and Popular Culture. London: Paul Chapman Publishing.

Mayer, R. 1844. "Kleinere Schriften und Briefe [Smaller writings and letters]." Letter to Wilhelm Griesinger, 16 June 1844. Mayes, C. 2005a. Jung and Education: Elements of an Archetypal Pedagogy. Maryland: Rowman and Littlefield.

Mayes, C. 2005b. "Ten Pillars of a Jungian Approach to Education. The Aesthetic in Education." ENCOUNTER: Education for Meaning and Social Justice 18 (2): 30-41.

Parry, R. L. 2014. "Popular Culture, Participation and Progression in the Literacy Classroom." Literacy 48 (1): 14-22.

Robertson, S. M. 1963. Rosegarden and Labyrinth: A Study in Art Education. New York: Barns \& Noble.

Samuels, A. 2004. "Jung. Century of the Self." Motion picture, BBC Four, London. Written and directed by Adam Curtis. Schön, D. A. 1983. The Reflective Practitioner: How Professionals Think in Action. New York: Basic Books.

Taylor, G. R., and L. MacKenney. 2008. Improving Human Learning in the Classroom: Theories and Teaching Practices. Lanham: Rowman \& Littlefield Education.

Tierney, R. J., E. Bond, and J. Bresler. 2006. "Examining Literate Lives as Students Engage with Multiple Literacies." Theory into Practice 45 (4): 359-367.

Todorov, T. 1984. Mikhail Bakhtin: The Dialogical Principle. Manchester: Manchester University Press.

Visser, W. 2011. "Schon: Design as a Reflective Practice." Collection on Art, Design \& Psycholog 2: 21-25.

Von Franz, M. L. 1964. "The Process of Individuation." In Man and his Symbols, edited by C. G. Jung, M. L. von Franz, J. L. Henderson, J. Jacobi, and A. Jaffe, 158-229. Garden City: Doubleday \& Company.

Walsh, M. 2011. Multimodal Literacy: Researching Classroom Practice. Newtown: Primary English Teaching Association.

Willett, R. 2005. "'Baddies' in the Classroom: Media Education and Narrative Writing." Literacy 39 (3): $142-148$.

Willett, R. 2014. "Remixing Children's Cultures: Media-Referenced Play on the Playground." In Children's Games in the New Media age: Childlore, Media and the Playground, edited by A. Burn, and C. Richards, 133-152. Farnham: Ashgate.

Wissman, K., and L. Vasudevan. 2012. "Re-Writing the Stock of Stories Urban Adolescents." In Reconceptualizing the Literacies in Adolescents' Lives: Bridging the Everyday/Academic Divide, edited by D. E. Alvermann, and K. A. Hinchman, 160-180. New York: Routledge.

Woodfall, A., and M. Zezulkova. 2016. "What "Children" Experience and "Adults" may Overlook: Phenomenological Approaches to Media Practice, Education and Research." Journal of Children \& Media 10 (1): 98-106.

Zezulkova, M. 2015. "Media Learning in Primary School Classroom: Following Teachers" Beliefs and Children's Interests." In Reflections on Media Education Futures, edited by S. Kotilainen, and R. Kupiainen, 159-169. 